\title{
28 Research Square \\ CaRBoKem: A Biofilter to Treat Heavy Metals by using the Household Waste Products
}

\section{Milan Maria Sajeev ( $\nabla$ milanmaria2349@gmail.com )}

Sahrdaya College of Engineering and Technology

\section{Uma Krishnakumar}

Assistant Professor, Department of Biotechnology Engineering;Sahrdaya College of Engineering and

Technology

\section{Merrin John}

Sahrdaya College of Engineering and Technology

\section{Amal Raj}

Sahrdaya College of Engineering and Technology

Hanna Thomas

Sahrdaya College of Engineering and Technology

\section{Research}

Keywords: Floatation, Chemical precipitation, Eggshell, nanofiltration

Posted Date: December 1st, 2020

DOI: https://doi.org/10.21203/rs.3.rs-113673/v1

License: (c) (i) This work is licensed under a Creative Commons Attribution 4.0 International License.

Read Full License 


\section{Abstract}

Environmental toxic waste from heavy metals along with minerals within the waste matter is one of the most significant issue in an Asian country. The activities like industrial operations particularly mining, agricultural processes and disposal of industry waste materials; their concentration has redoubled to hazardous levels. Major metals in industrial sewage represent $\mathrm{Cu}, \mathrm{Cr}^{3+}$ and $\mathrm{Pb}$ etc. So far, varieties of inexpensive strategies are reviewed for the removal of these metals. The various processes include chemical precipitation, reverse diffusion, electro qualitative analysis, nanofiltration and floatation. But these strategies have many disadvantages like high chemical agent demand, unpredictable metal particle elimination, and production of unhealthful sludge. Surface absorption method being terribly straightforward, economical, effective and versatile has become the most popular strategies for removal of unhealthful contaminants from waste matter. This paper gives a new idea for the utilization of natural materials as adsorbents for significant metal removal from industrial waste water. The components used are mustard plant roots, human hair and some common house hold waste products such as, egg shell and coconut shell. Utilizing their adsorbent properties in an efficient way, it can be used to filter industrial heavy metals which cause pollution.

\section{Introduction}

These day's toxins are discharged into water leading to water contamination. Numerous heavy metals from various industries like battery plants, metal processing industries, pharmaceuticals, hospitals, mining fields etc. are being discharged into the water bodies leading to unstable water for everyday use [2].Lead, Chromium, Copper etc are the heavy metals that induces toxicity plus carcinogenetic when present in high concentration [3]. In order to obtain dirt free and safe water, toxic chemicals and metals should be eliminated. The standard of our environment is decreasing day by day, means of giant cities reaching saturation points and unfit to cope with the rising pressure on their infrastructure [4].Major pollutants that contaminate the environment are sewage and industrial effluents. Most of the industries discharge wastewater. Environmental pollution especially from heavy metals and minerals in wastewater is the major concern in India [5].

Many methods have been undertaken in the process to remove these unwanted contaminants such as physio-chemical methods, a range of biological methods to a large extend nano based techniques. One of the most important treatment processes used in water and wastewater treatment is filtration. In water management, the aim is to fabricate effluent of good criterion so that it can be reused for various purposes [6]. A biofilter is a filter with linked biomass on the filter-media. Biofilters can be trickling filter, horizontal rock filter or granular activated carbon (GAC) or sand filter in water treatment plant. Biofilter applications are found in air, water, as well as wastewater treatment [7]. Biofiltration reduces odour and hydrogen sulphide $\left(\mathrm{H}_{2} \mathrm{~S}\right)$ emissions by $95 \%$ and ammonia $65 \%$ approximately. Biofilters are operated in automatically ventilated buildings or on the pit fans of naturally ventilated buildings [8]. A biofilter is a layer of material that is organic, mixture of compost that supports a population of microbes. Biofilter 
performance is controlled by amount of time the odorous air spends in the biofilter and also the moisture content of the filter material [9].

The biofilter we have prepared with the sole purpose to attain environmental sustainability by using the household waste such as mustard plant roots, eggshell, human hair and coconut shell. Mustard plant roots have high quality adsorbent properties and may be a thriving technique in purification of water due to the compounds in roots that contains the amount of nitrogen, sulfur and organic compounds such as carboxylic acids. These acids are charged such that their negatively charged electron pairs are exposed, meaning they can combine with metals in the water that typically contain a positive charge. Eggshells are a very dependable adsorbent due to its carbonate content. Keratin is the main constituent of wool, hair, feathers, horn, and nail. Keratinous materials, wool, feather and hair have been used to absorb metal ions from solution in their native state and with suitable chemical pre-treatment; the adsorption capacity for these ions can be drastically enchanced. The main idea of our project is to see how efficient mustard plant roots, eggshell, human hair and activated carbon are absorbing heavy metals. We have devised our own protocol and decided various parameters which we thought suited the best.

\section{I. Materials And Methods}

\section{A. Materials Required}

Mustard seeds, Egg shell, Human hair, Coconut shell, Bell Jar, Beaker, Soil, 0.5 $\mathrm{M} \mathrm{H}_{2} \mathrm{O}_{2}, 1.5 \mathrm{M} \mathrm{ZnCl}_{2}, 0.1 \mathrm{M}$ $\mathrm{HCl}$ and $\mathrm{NaOH}$ solutions were used to alter the $\mathrm{pH}$. All the chemicals were of laboratory grade used in our college. The Industrial Water Sample 1 was collected from a sheet metal industry; Industrial Water Sample 2 was collected from a paint industry. We measured the absorbance of heavy metals by Atomic Absorption Spectrometer (AAS).

\section{B. Preparation of solutions}

To prepare $0.5 \mathrm{M} \mathrm{H}_{2} \mathrm{O}_{2}$ we added $10 \mathrm{~g}$ of $\mathrm{H}_{2} \mathrm{O}_{2}$ in to $500 \mathrm{ml}$ of deionized water. Likewise we added $10 \mathrm{~g}$ of $\mathrm{ZnCl}_{2}$ in to $100 \mathrm{ml}$ of deionized water to prepare $1.5 \mathrm{M} \mathrm{ZnCl}_{2}$. We labeled the samples with respect to their $\mathrm{pH}$, contact time of $60 \mathrm{~min}$ and $90 \mathrm{~min}$ at room temperature. Afterwards filtered the solutions and absorbance was taken using ASS.

\section{Preparation of Adsorbents}

\section{Cultivation of Mustard plant roots}

Mustard seeds were taken and soaked in water for about 5 hours, later laid them on cotton and allowed them to sprout. After sprouting in a tray they were grown for 3 weeks in the soil. 


\section{Preparation of Eggshell}

Twenty eggshells were collected from daily kitchen waste and washed by normal tap water followed by distilled water. The eggshells were left to dry on blotting paper to absorb surplus water and then subjected to the hot air oven at $50{ }^{\circ} \mathrm{C}$ for 2 days. Once totally dehydrated we pulverized and shred eggshells to fine particles with mortar and pestle followed by a mixer. Later we sieved the crushed adsorbent to obtain a homogenous dimension around $0.05 \mathrm{~cm}$.

\section{Production of Activated Carbon}

Some amount of coconut shell was cleaned to remove impurities such as coconut fiber and sand. Dried under the sun for 7 hours and followed by 3 hours in an oven to obtain charcoal. The charcoal was crushed to $0.5 \mathrm{~mm}$ mesh size. About $200 \mathrm{~g}$ of this chrushed charcoal was introduced into $1.5 \mathrm{M} \mathrm{ZnCl}_{2}$ and stirred to form a paste/slurry. This was heated for about 5-6 hours and allowed to chill at room temperature, thus impregnated with $\mathrm{ZnCl}_{2}$. This is called doping. The doped charcoal was heated in an electric furnace to $450{ }^{\circ} \mathrm{C}$ for an hour and allowed to cool in air. Then it was carefully washed to eradicate traces of $\mathrm{ZnCl}_{2}$.

\section{Preparation of human hair}

Hair samples were obtained from local barbershops. Human hair samples were washed with detergent and rinsed several times with deionized water and left to dry at room temperature. The hair was cut to an approximate length of less than $5 \mathrm{~mm}$ by using scissors. $20 \mathrm{~g}$ of washed dried biomaterial was weighed out and soaked in $0.5 \mathrm{M} \mathrm{H}_{2} \mathrm{O}_{2}$ and solution was filtered. Finally, the treated and cleaned biomaterials were dried at room temperature.

\section{I I. Packging Of A Biofilter}

The roots of the mustard plant were grown in the soil was cut and kept as first layer, followed by egg shell layer. The third layer and fourth layer were constituted by human hair and activated carbon respectively.

\section{V. Method}

The industrial waste water containing heavy metal is passed through each layer. This setup for filtration was arranged as layers in the bell jar and the contact time used was 60 min and 90 min respectively. $\mathrm{pH}$ and absorption of the sample was checked by subjecting to the AAS.

\section{Effect of pH on Adsorption}


The range of $\mathrm{pH}$ used was 4-7.The adjustments were done using $0.1 \mathrm{M}$ solution of $\mathrm{HCl}$ and $\mathrm{NaOH}$. Later the flasks were subjected to contact time of $60 \mathrm{~min}$ and $90 \mathrm{~min}$ respectively. Then the filtrate was taken and AAS was used to verify the absorption of the heavy metals.

\section{Effect of Contact time on Absorption}

After $60 \mathrm{~min}$ and $90 \mathrm{~min}$ of contact time filtration occurred and the adsorption was checked by using AAS.

\section{Results And Disscusion Effect on pH of Adsorption}

At lesser $\mathrm{pH}$ values the adsorbance was a found to be smaller compared to higher $\mathrm{pH}$ values. It could be because at lesser values the adsorption could have been contrast due to the competitive interactions between the heavy metal ions and the hydrogen ions which restrict the adsorption. The presence of carbonate groups in the adsorbents was identified at higher $\mathrm{pH}$ values. In general best results were obtained at $\mathrm{pH} 7$.

\section{Effect of Contact time on Adsorption}

The adsorbance will be higher at larger surface area and contact time. Better results were obtained when exposed for a contact time of $90 \mathrm{~min}$. The results of both filtered and unfiltered sample testing were done in the College of Veterinary and Animal Sciences, Mannuthy. 
Table 1

Table of heavy metals with parameter

\begin{tabular}{|c|c|c|c|c|c|}
\hline Metal & $\mathrm{pH}$ & Absorbance & Contact time & Unfiltered & Filtered \\
\hline \multirow[t]{4}{*}{$\mathrm{Cu}$} & 4 & 0.2493 & $60 \mathrm{~min}$ & \multirow[t]{4}{*}{$37.92 \mathrm{ppm}$} & \multirow[t]{4}{*}{$8.50 \mathrm{ppm}$} \\
\hline & 5 & 0.3283 & $60 \mathrm{~min}$ & & \\
\hline & 6 & 0.034 & $90 \mathrm{~min}$ & & \\
\hline & 7 & 0.0901 & $90 \mathrm{~min}$ & & \\
\hline \multirow[t]{4}{*}{$\mathrm{Pb}$} & 4 & 0.2204 & $60 \mathrm{~min}$ & \multirow[t]{4}{*}{$12.01 \mathrm{ppm}$} & \multirow[t]{4}{*}{3.86 ppm } \\
\hline & 5 & 0.006 & $60 \mathrm{~min}$ & & \\
\hline & 6 & 0.1908 & $90 \mathrm{~min}$ & & \\
\hline & 7 & 0.0184 & $90 \mathrm{~min}$ & & \\
\hline \multirow[t]{4}{*}{$\mathrm{Cr}^{3+}$} & 4 & 0.1881 & $60 \mathrm{~min}$ & \multirow[t]{4}{*}{$6.77 \mathrm{ppm}$} & \multirow[t]{4}{*}{$1.82 \mathrm{ppm}$} \\
\hline & 5 & 0.0908 & $60 \mathrm{~min}$ & & \\
\hline & 6 & 0.1432 & $90 \mathrm{~min}$ & & \\
\hline & 7 & 0.2007 & $90 \mathrm{~min}$ & & \\
\hline
\end{tabular}

\section{I. Conclusion}

The elimination of heavy metals $\mathrm{Cu}, \mathrm{Pb}$ and $\mathrm{Cr}^{3+}$ using mustard plant roots, eggshell, human hair and activated carbon as adsorbents was carried out by various parameters such as contact time and $\mathrm{pH}$ values. The best results were observed at the conditions, having $\mathrm{pH}$ value 7 and contact time of $90 \mathrm{~min}$. As the size of adsorbent was small the competence of adsorption was increased; also these household wastes are economical and the manufacture process is very sustainable. Moreover this will not cause any damage to the future of environment and it is very safe to use. At the primary stage itself the filtration was achieved and it was found that all these adsorbents were finest for adsorption of heavy metals from waste water. Upgrading the size of particles to nanoscale was found to be futuristic. Also element modifications may be done on the household waste to amplify the absorbance capability.

\section{Abbreviations}

AAS: Atomic Absorption Spectrometer.

\section{Declarations}




\section{CONSENT FOR PUBLICATION}

Authors have agreed to submit it is in current from for consideration for publication in the journal.

\section{AVALIABILTY OF DATA AND MATERIALS}

The authors approved the availability of data and materials for publishing the manuscript.

\section{COMPETING INTERESTS}

The authors declare that they have no competing interests.

\section{FUNDING}

No funding was received for the research project.

\section{AUTHORS INFORMATION}

Dr.Uma Krishnakumar, Milan Maria Sajeev, Merrin John, Amal Raj, Hanna Thomas all contributed equally to this work.

\section{Affiliations}

All belong to the Department of Biotechnology, Sahrdaya College of Engineering and Technology Kodakara, Thrissur, Kerala, India.

\section{CONTRIBUTIONS}

All authors read and approved the final manuscript.

\section{ACKNOWLEDGEMENTS}

We would like to express our immense gratitude and profound thanks to all those who helped us to make this project a grand success. At this moment we express our thanks to God almighty for all the blessings for the successful completion of this project. We thank our executive director Rev. Fr George Pareman, Director Dr. Sudha George Valavi, Principal Dr. Nixon Kuruvilla, and Head of department Dr. Ambili 
Mechoor for providing us with this wonderful opportunity. We extend our deep sense of gratitude to Mrs. Dr Uma Krishnakumar, our project guide for her whole hearted support during the making of this project. We are deeply greatful to Ms. Vidhya, lab assistant for her immense support with which this project became a grand success. Last but not the least we extent our gratitude to all our classmates and to our parents who supported us throughout this project.

\section{References}

1. Journal of Hazardous Materials Volume 137, Issue 2

2. Paul B Tchounwou Clement G Yedjou, Anita K Patlolla. Heavy Metals Toxicity and the Environment

3. Chang-Sik Ha.Periodic Mesoporous Organosilicas pp 219-266 PMOs for Adsorption

4. Neeta Singh, Dr.S.K.Gupta. Adsorption of heavy metals: A Review

5. Vijaya VShegokar1, Dilip S.Ramteke2, Pravin U. Meshram. Design and Treatability studies of low cost Biofilter in grey water treatment.

6. Adhithya Ram PN-Project report on studies on natural fibrous materials as fixed aerated beds for domestic wastewater treatment

7. Lide Chen. Biofiltration: Mitigation for Odor and Gas Emissions from Animal Operations

8. Omar Kalluf. Biofilter Configuration and Elements

\section{Figures}

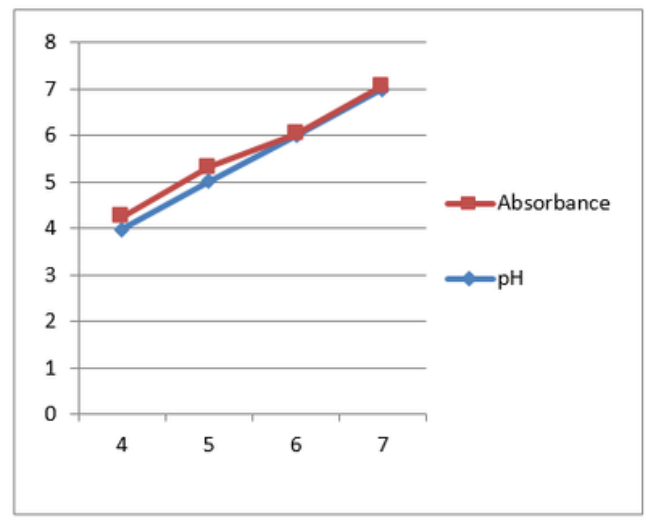

(a) $\mathrm{pH}$ of Copper

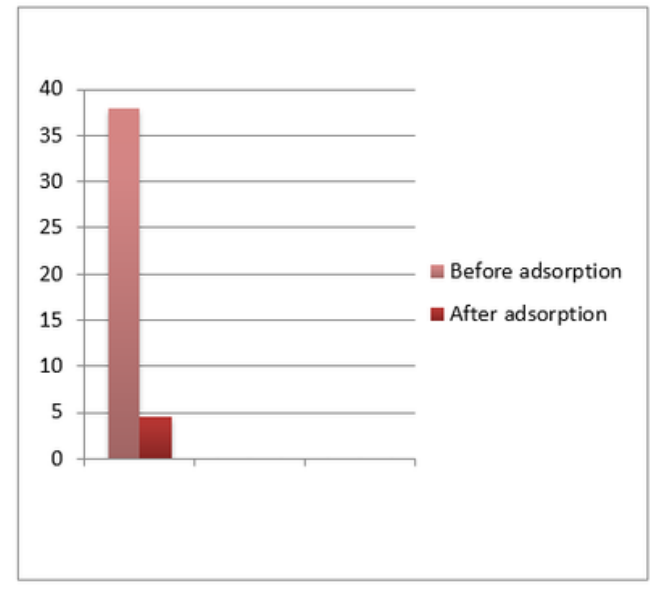

(b) The quantity of copper removed after adsorption

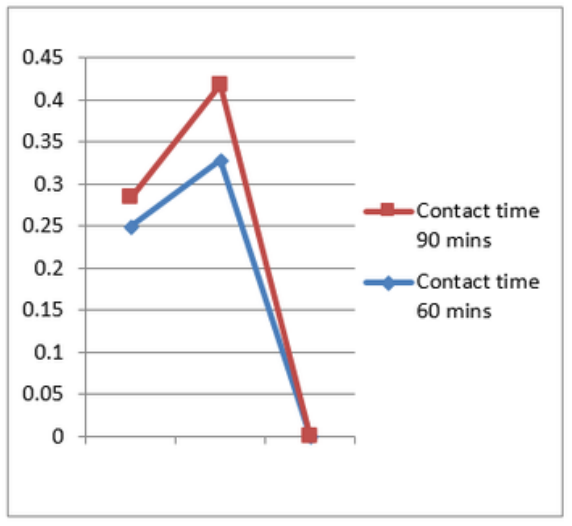

(c) With regard to contact time

Figure 1

Graphs for copper with parameters. 


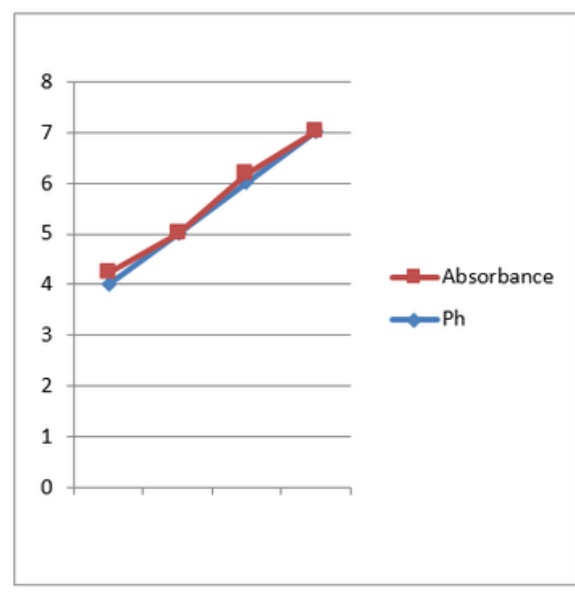

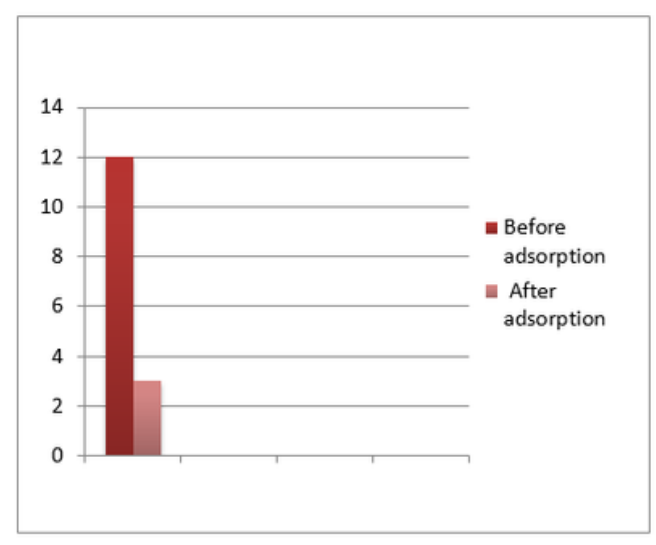

(b) The quantity of Lead removed after adsorption

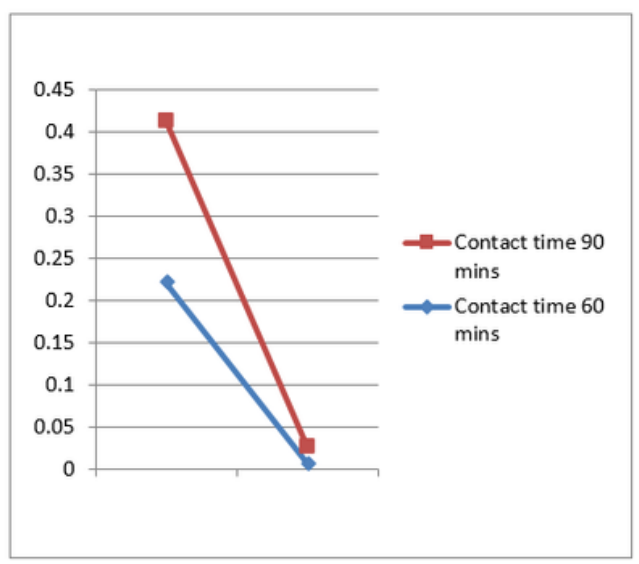

(c) With regard to contact time

(a) $\mathrm{pH}$ of Lead

\section{Figure 2}

Graphs for Lead with parameters.

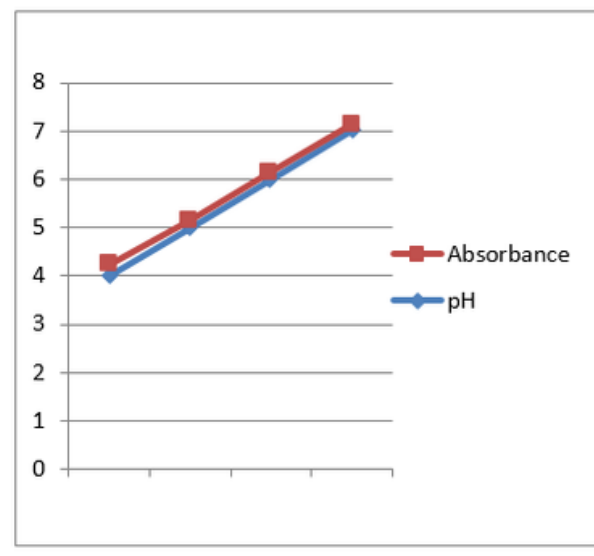

(a) For $\mathrm{pH}$ of chromium

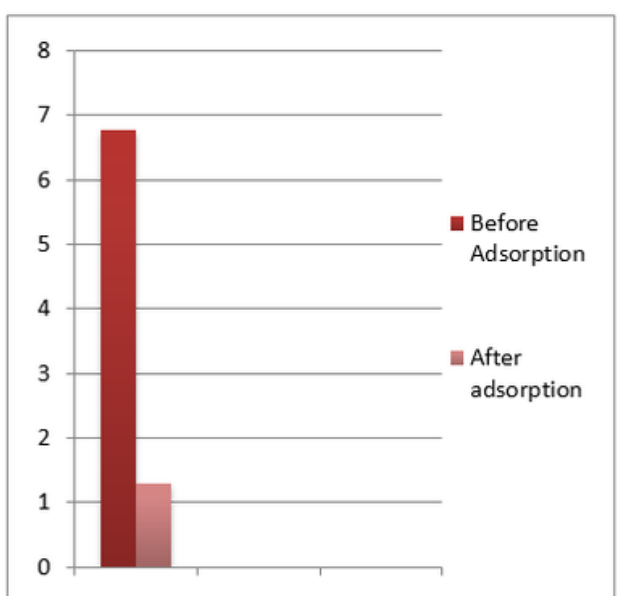

(c) With regard to contact time

(b) The quantity of chromium removed after adsorption

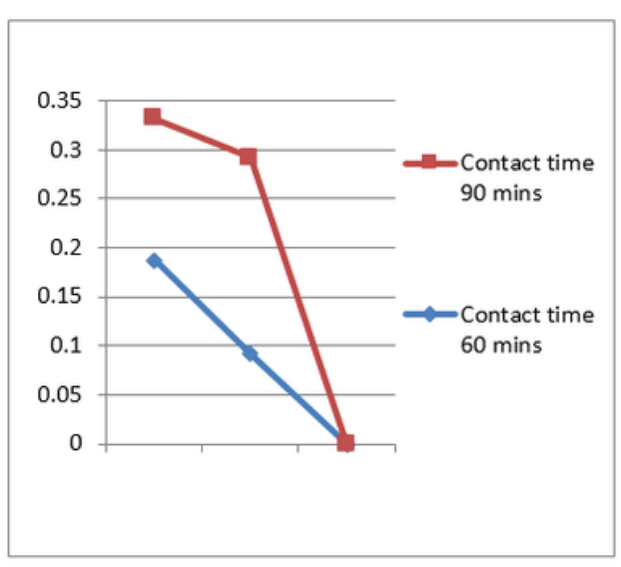

\section{Figure 3}

Graphs for Chromium with parameters

\section{Supplementary Files}

This is a list of supplementary files associated with this preprint. Click to download.

- CarbokemGraphicalAbstract.docx 